\title{
Construindo uma cena musical independente em Niterói no início do século XXI: o estudo de caso dos coletivos Araribóia Rock e Ponte Plural \\ Micael Herschmann
}

\section{Resumo}

Tomando como referência não só as obras de importantes especialistas como Straw, Yúdice, Jenkins e Maffesoli, mas também a pesquisa empírica realizada entre 2010 e 2013 - investigação construída a partir da coleta, seleção e análise de enunciados veiculados na mídia impressa tradicional e material postado em redes sociais, de observações de campo e entrevistas semiestruturadas realizadas com os atores sociais - produtores, músicos e fãs/consumidores

- procurou-se fazer um balanço dos desafios e perspectivas (especialmente nas últimas duas décadas) para o desenvolvimento de uma cena musical independente na cidade de Niterói.

\section{Palavras-Chave}

Comunicação. Cultura Urbana. Cenas Musicais. Circuito Fora do Eixo. Festivais Independentes.

Micael Herschmann I micaelmh@pq.cnpq.br Professor do Programa de Pós-Graduação em Comunicação da UFRJ

\section{Introdução}

No dia 31 de maio de 2013, o jornal 0 Globo estampava na primeira página do Segundo Caderno a seguinte manchete sobre a emergência de novos talentos musicais: "A geração 2010". Nela o crítico musical e jornalista Carlos Albuquerque (2013) destacava a trajetória de jovens artistas e grupos que despontavam na nova cena local e nacional tais como Tereza, Apollo, Opala, Mahmundi, João Brasil, Secchin, Lucas de Paiva e Maria Luiza Jobim. 0 que chamava a atenção na matéria jornalística ${ }^{1}$ é que quase todos estes artistas têm algum nível de articulação com o Ponte Plural (PP), coletivo que tem como uma de suas principais diretrizes ${ }^{2}$ a dinamização da cena independente da cidade de Niterói. ${ }^{3}$

Aparentemente não há nada demais nesta repercussão midiática, tendo em vista o dinamismo e a dedicação com que os coordenadores desse coletivo vêm imprimindo desde 2010, dedicando-se prioritariamente a 
lançar e promover o trabalho de novos talentos que trabalham com diferentes gêneros musicais. ${ }^{4}$

Entretanto, há um detalhe que faz com este fato seja celebrado pelos atores como uma grande conquista. Como é de conhecimento de grande parte do público: tradicionalmente há uma grande concentração das atividades culturais e de investimentos da macrorregião (desse Estado) localizada especificamente na cidade do Rio de Janeiro, o que acaba invariavelmente trazendo inúmeras consequências negativas para as áreas vizinhas. Uma delas, a cidade de Niterói apesar de ser um local aprazível e que possui um excelente Índice de Desenvolvimento Humano
(IDH) - tem enfrentado grandes dificuldades em alcançar algum patamar de protagonismo regional - e tem levado os moradores da cidade a construírem um imaginário que remete a ideia de certa "crise identitária" na localidade. ${ }^{5}$ Ou seja, em função da proximidade geográfica e do glamour da megalópole vizinha - e do fato dos "olhares" do público e dos meios de comunicação estarem focados apenas para um lado da baía, isto é, estarem invariavelmente voltados para a chamada "cidade maravilhosa" -, Niterói, também conhecida como "cidadesorriso" e "terra de Araribóia", apesar de uma vida cultural significativa e, para alguns, "vibrante", ${ }^{6}$ permanece sendo considerada basicamente como

Cabe salientar que esta matéria jornalística teve uma enorme repercussão pelo destaque que recebeu por sua veiculação na página de abertura do mais importante caderno cultural do Rio - que pertence ao jornal de maior circulação da cidade -, fato inédito para a trajetória da chamada "cena independente de Niterói", até então. Evidentemente, nos últimos anos, em várias oportunidades, o PP ganhou também algum destaque na mídia tradicional como pode ser constatado nas matérias de Albuquerque (2011), Lo Bianco (2012) e Dias (2011).

Outra diretriz bastante visível na atuação do PP é a dinamização também de cenas musicais do interior do Estado do Rio de Janeiro. Para mais detalhes confira : <www.ponteplural.com.br >. Acesso: 12 jun. 2013.

Segundo Daniel Domingues, uma das lideranças do PP, em entrevista concedida ao autor em 19 de julho de 2010: na cena independente atual, dificilmente os coletivos têm exclusividade sobre 0 trabalho das bandas, tal como tinham as gravadoras e produtores no século passado. 0 PP articula não as carreiras dos músicos, mas engajam-se por projeto ou articulam-se pontualmente para realizar alguma iniciativa.

Em função do dinamismo que imprimiram ao PP, os coordenadores e líderes desse coletivo, ganharam em 2012 o prêmio Brasil Criativo, agraciado pelo Ministério da Cultura.

Para mais detalhes a respeito da relação identitária complexa e conturbada entre Niterói e Rio de Janeiro, confira Luz (2008).

Ao longo das últimas décadas, a cidade vem abrigando academias literárias, institutos históricos, grupos de poetas, músicos, artistas, concursos literários, exposições, festivais de música, entre outras atividades, numa quantidade impressionante para suas relativamente reduzidas dimensões populacionais. Poder-se-ia dizer que Niterói é uma cidade bastante pulsante em atividades intelectuais e culturais, o que lhe valeu o título de "celeiro de artistas", de inegável "vocação cultural" e a certeza de que lá se produzia uma ambiência cultural muito própria, que de forma alguma poderia ser considerada um reflexo apenas do que ocorre no Rio de Janeiro. Para mais informações sobre o dinamismo de Niterói, especialmente nos últimos anos, consulte Luz (2008). 
uma cidade "satélite" ou "dormitório", que atende a cidade capital do Estado.

Tendo em vista que existe um "coletivo" de rock independente que atua na região desde 2004, 0 Araribóia Rock, ${ }^{8}$ que jamais conseguiu atingir este patamar de projeção nacional - apesar de ter movimentado a cena local e ter sido importante para aglutinar os músicos e segmentos expressivos de fãs de rock da localidade nos seus eventos -, poder-se-ia indagar: como o Ponte Plural conseguiu que a cena de Niterói alcançasse este nível de visibilidade? Que conjunto de estratégias foi adotado?

Sempre é importante recordarmos que estamos assistindo no universo musical - seja no âmbito do mundo indie ou do mainstream ${ }^{9}-$ a um contexto de transformações profundas (HERSCHMANN, 2011), isto é, como já ressaltado em outros trabalhos publicados, a indústria da música está vivenciando um período de transição neste início do século XXI (HERSCHMANN, 2010a). Assim, presenciam-se mudanças significativas na estrutura da sua cadeia produtiva: dentre as muitas alterações, constata-se com grande perplexidade, por exemplo: a "resistência" dos consumidores em pagar pelos fonogramas; a redução do casting de artistas e do quadro de funcionários das grandes empresas; a crise da noção de álbum que vai deixando de ser o objetivo central desta indústria ou a mercadoria mais valorizada nesta dinâmica de produção e consumo; 0 desaparecimento de antigas funções no setor e, ao mesmo tempo, 0 surgimento de novas profissões que empregam especialmente as novas tecnologias. Essas transformações na indústria da música estão relacionadas, em grande medida, à emergência de uma Era Digital. Evidentemente, não se trata de ruptura completa em relação ao paradigma anterior, mas do largo emprego dos processos comunicacionais e das novas tecnologias que vêm afetando de forma significativa a maneira como organizamos e estruturamos a vida social hoje (HERSCHMANN, 2010a). Passado um momento de maior perplexidade dos profissionais da indústria da música e de um otimismo de certo modo "ingênuo" quanto ao potencial da web e da "cauda longa" (ANDERSON, 2007), especialmente daqueles que trabalham nas grandes gravadoras - os que não foram demitidos ou que não optaram por sair do mainstream -, é possível afirmar que este setor da produção cultural está se reestruturando. Analisando os últimos

A noção de "coletivo" é empregada neste artigo como categoria nativa, largamente utilizada no universo da música e cultural (especialmente pelo setor independente) para designar o trabalho colaborativo e solidário (das redes) que é realizado de forma mais ou menos engajada pelos atores sociais, buscando alcançar resultados individuais e coletivos, mercantis e não mercantis.

Mais informações a respeito da linha de atuação do Araribóia Rock, ver: <http://www.arariboiarock.com.br>. Acesso em: 13 jun. 2013.

Ainda que categorias como indies, majors, underground e independente sejam bastante imprecisas (HERSCHMANN, 2011), são empregadas neste artigo como categorias nativas que são largamente utilizadas no universo da música pelos atores sociais. 
dados divulgados pelos institutos e associações de música nacionais, é possível constatar que novos negócios e hábitos de consumo estão se consolidando no mundo, ainda que estes não sejam "visíveis" - pelos níveis de informalidade e pela falta de interesse em gerar certos tipos de indicadores culturais do setor da música - e/ ou que os benefícios diretos e indiretos destas iniciativas não se reflitam em uma recuperação mais efetiva da chamada grande indústria da música (HERSCHMANN, 2013a; YÚDICE, 2011). Esses business, que não são exatamente "novos", apesar de alguns serem inovadores - do ponto de vista tecnológico ou do tipo de relação que se estabelece com os usuários-consumidores -, estão associados às apresentações musicais "ao vivo" 10 - shows avulsos, circuitos, cenas e festivais independentes - e às novas estratégias de comercialização de fonogramas, grande parte das vendas está articulada às estratégias desenvolvidas pelas empresas junto às plataformas multimídia de games, aos aparelhos celulares e aos sites da internet.

Assim, retornando ao eixo central deste artigo, cabe ressaltar que se busca aqui comparar as estratégias desenvolvidas pelos coletivos do Araribóia Rock e Ponte Plural na tentativa de ambos de dinamizarem a "cena musical" (STRAW, 1997, 2006) local. A partir da análise de matérias veiculadas na mídia e nas redes sociais, de observações de campo e entrevistas semiestruturadas realizadas com os atores sociais (produtores, músicos e consumidores) procurou-se fazer um balanço das dificuldades e perspectivas para desenvolvimento da cena indie de Niterói. ${ }^{11}$

Este artigo tomou como norte alguns pressupostos: a) primeiramente que, por um lado, o Araribóia Rock foi importante para a cena local na primeira década do século XXI; e, por outro, que a partir da segunda década desse mesmo século, 0 protagonismo vem sendo exercido cada vez mais

Parte-se da premissa de que os concertos ao vivo vêm crescendo em importância dentro da indústria da música atual, e que isso está relacionado ao alto valor que essa "experiência" (MAFFESOLI, 1987; PINE; GILMORE, 2001) tem no mercado, isto é, à sua capacidade de mobilizar e seduzir os consumidores e aficionados a despeito: a) do preço a ser desembolsado (muitas vezes bastante alto) para assistir ao vivo às performances; b) e da alta competitividade que envolve as várias formas de lazer $\mathrm{e}$ entretenimento na disputa de um lugar junto ao público hoje, no dia a dia do mundo globalizado. Isto se deve ao fato de que a música ao vivo oferece a possibilidade de uma experiência coletiva musical que é importante para os atores sociais na atualidade. Em trabalhos anteriores realizados destacou-se que o grande interesse pela música ao vivo está relacionado ao alto valor agregado da experiência musical associada aos vetores da sociabilidade, da estética e da estesia. Ou seja, por um lado, a experiência de consumir fonogramas individualmente de forma não mercantil (através de trocas de arquivos) é largamente praticada e, por isso, os fonogramas vem perdendo rapidamente e significativamente valor comercial para os consumidores (indivíduos estão dispostos a pagar muito pouco ou nada por isso); e, por outro lado, a experiência coletiva ou social da música (associada aos concertos ao vivo) está cada vez mais valorizada: a música emergiria hoje, portanto, como élan social, uma espécie de "paisagem sonora", que permite que os indivíduos vivenciem trocas, façam catarses, gerem memórias e identidades coletivas que são atualizadas nos eventos musicais (HERSCHMANN, 2010a).

Agradeço ao CNPq e a FAPERJ pelo apoio a esta investigação. Agradeço ainda não só à Cíntia Sanmartin pelo inestimável intercâmbio, mas também às minhas dedicadas auxiliares de pesquisa de iniciação científica - Jaqueline Neves da Silva, Tássia Veríssimo e Ana Clara Ribeiro pela colaboração no levantamento de inúmeras informações desta pesquisa sobre a cena de Niterói. 
pelo Coletivo Ponte Plural nesta localidade; b) e, em segundo lugar, que apesar de ambos utilizarem atualmente a internet - empregam as redes sociais da $w e b$ como forma de mobilização do público e de circulação de fonogramas e de conteúdos diversos, tais como flyers, fotos, releases, críticas, matérias de blogs e revistas especializadas etc. - e buscarem apoio através das leis fomento e de incentivo a cultura (disputam os editais públicos e tentam se articular com empresas patrocinadoras) as estratégias desenvolvidas pelo $\mathrm{AR}^{12} \mathrm{e}$ as promovidas pelo PP operam a partir de lógicas um pouco distintas..$^{13} \mathrm{~A}$ hipótese central, portanto, é que 0 PP atua de forma mais colaborativa, potencializando as sinergias que são realizadas pelos eventos de música ao vivo que compõe o Circuito Fora do Eixo (CFE): com isso eles transformam a cena de Niterói em uma espécie de "nó ou ponto de uma rede" que pode ser simultaneamente local/nacional/ transnacional e com isso podem oferecer concertos de alta qualidade com um elenco de artistas capazes de atrair o grande público, de ambos os lados da Baía de Guanabara. Além disso, os artistas de Niterói, através do coletivo PP, tocam também com frequência em importantes salas do Rio (como Studio RJ e Circo Voador) e, com isso, não só se supera uma dualidade (e até certa rivalidade) regional, mas também se realiza um importante trabalho de formação de público, para além das fronteiras da microrregião de Niterói. Como sugere o próprio nome do coletivo buscam construir uma "ponte" e articulação não só com o Rio, mas com diferentes redes (por isso "plural") e, com isso, acabam também "colocando no mapa", artistas de Niterói - tais como a Banda Tereza, Facção Caipira, Rivotril 2 mg e Ludi Um e os Únicos -, portanto, conseguem, em grande medida, que os grupos musicais que promovem adquiram visibilidade na "nova indústria musical" (fragmentada e cada vez mais centrada na música ao vivo, seja na forma de concertos avulsos ou festivais) (HERSCHMANN, 2010a).

\section{Música ao vivo e crescimento dos festivais independentes no Brasil no início do século XXI}

Poder-se-ia afirmar que nunca se viu realizar tantos festivais musicais - do mainstream e do circuito independente - no país como na atualidade. No Brasil, só vinculado às duas principais redes de festivais indies do país - Rede Brasil de Festivais (organizado pelo Circuito Fora do Eixo) e Festivais Brasileiros Associados - temos quase

Em geral o AR sempre buscou construir um "polo de música alternativo" - o maior do Brasil situado na cidade do Rio -, levando a cabo iniciativas tradicionalmente centradas em "eventos microrregionais de rock enraizados territorialmente", que gravitam especialmente em torno do gênero rock - ou da sua fusão com outros gêneros -, em geral, aquele produzido por artistas de Niterói.

0 PP em geral, emprega "estratégias multiterritoriais de potencialização de redes". 0 PP se articula com artistas de diferentes localidades do país e também de Niterói, os quais trabalham com vários gêneros musicais, realizando eventos não só nesta cidade, mas por todo Brasil, através da Rede Brasil de Festivais (vinculada ao Circuito Fora do Eixo). Mais detalhes, ver: <www.ponteplural. com.br >. Acesso: 12 jun. 2013. 
130 eventos musicais promovidos em todo o país, especialmente no interior - que mobilizam mais de 500 grupos musicais e um público jovem (em sua maioria na faixa etária entre 16 e 30 anos) de aproximadamente 400 mil pessoas por ano. ${ }^{14}$ Isso sem falar dos megafestivais que atraem anualmente mais de dois milhões de pessoas, nas principais capitais do país, tais como Nokia Trends, Skol Beats, Tim Festival, Festival Bourbon, BMW Jazz Festival, entre outros. Ao mesmo tempo, festivais internacionais como, por exemplo, Rock in Rio, SWU, Creamfields, Videogame Live, Lollapalooza e Sonar tornam-se cada vez mais numerosos e são replicados no Brasil e em diversas localidades do globo (HERSCHMANN; QUEIROZ, 2012).
Alguns se questionam se a era dos festivais está de volta, pelo menos no Brasil. ${ }^{15} \mathrm{Se}$, por um lado, temos a retomada dos grandes festivais organizados pelos conglomerados de comunicação e entretenimento (em parceria com grandes empresas); por outro lado, assistese atualmente ao boom de eventos indies que são formatados na forma de mostras/feiras, organizados por coletivos de artistas e produtores (independentes), com o apoio de associações e que se utilizam - para captar recursos públicos e privados - de leis de incentivo e editais de cultura e que são veiculados especialmente em mídias alternativas (HERSCHMANN, 2010). ${ }^{16}$ No que se refere aos festivais independentes, que não param

14 Uma história recente e resumida dos festivais certamente ressaltaria que, na última década do século XX, começou a se formar um novo circuito nacional de festivais independentes, o qual passou a gravitar em torno da ABRAFIN e o Circuito Fora do Eixo (HERSCHMANN, 2010b; YÚDICE, 2011). Com o sucesso consolidado no início do século XXI, vieram as discordâncias, as acusações e disputas de poder: aliás, no ano de 2011 e 2012, as brigas entre os atores se intensificaram entre as lideranças e ocorreu um racha profundo entre os festivais mais antigos (e, em geral, maiores) e os festivais menores e mais recentes. Hoje a ABRAFIN está extinta e há duas redes de coletivos muito fortes e atuantes no país: de um lado, temos a Rede Brasil de Festivais, vinculada ao Circuito Fora do Eixo, que envolve a realização de 107 festivais em 88 cidades e mais de seis mil artistas; e, do outro lado, temos cerca de 20 festivais mais tradicionais tais como Abril Pro Rock, Mada, Goiania Noise, Demosul, os quais juntos estão se organizando em torno da associação Festivais Brasileiros Associados (ALVES, 2013).

15 Analisando a história da música brasileira podem-se identificar dois momentos marcantes na trajetória dos festivais: a) um primeiro - nos anos de 1960 (Festivais da Canção, na TV Excelsior e Record) e nos de 1980 e 1990 (não só o Festival da Nova Música Popular Brasileira, mais conhecido como MPB 80, na TV Globo, mas também a realização de megaeventos como 0 Rock in Rio, Hollywood Rock e Free Jazz) - organizado pelas emissoras de televisão, com apoio das grandes gravadoras e de outros veículos de comunicação de massa (CORRÊA, 2012; HOMEM DE MELO, 2003; NAPOLITANO, 2001; RIBEIRO, 2002; VILARINO, 1999); b) e, um segundo, na primeira década do século XXI, em que identificamos eventos com um perfil mais atrelado ao mercado do mainstream e, outros, mais identificados ao circuito independente (HERSCHMANN, 2010b).

Analisando a história desses eventos, é possivel atestar que os festivais do século XXI têm a mesma função dos realizados na década de 1960: revelar e/ou promover talentos. No restante, possuem perfis bastante distintos. Essas diferenças estão ligadas às mudanças que o mundo da música experimentou nos últimos anos. A década de 1960 foi o período em que a televisão se consolidou como principal meio de divulgação de música popular, superando o rádio. Os festivais do século passado eram promovidos por emissoras de tevê e possibilitaram que artistas como Caetano Veloso, Gilberto Gil, Nara Leão e Chico Buarque passassem a fazer parte do grande business da música. É interessante constatar que hoje o contexto mudou significativamente: ainda que os produtores e artistas indies invistam na ideia de "autenticidade", é possivel constatar que as fronteiras entre 0 universo do mainstream e 0 independente se tornaram muito mais "porosas" hoje (FREIRE FILHO, 2003). Além disso, não só a internet vem substituindo mídias tradicionais e massivas como principal meio de divulgação de música, mas também as grandes gravadoras enfrentam dificuldades financeiras, e os artistas, novos ou não, sobrevivem, sobretudo através de concertos ao vivo e da presença em circuitos e cenas alternativos (HERSCHMANN, 2010b; 2011). 
de crescer por todo o país, vale destacar algumas estratégias que visam garantir-lhes visibilidade e sustentabilidade: utilizam recursos de leis de incentivo à cultura, moedas complementares e iniciativas de crowdfounding; empregam o potencial interativo das novas tecnologias digitais visando formação, divulgação e mobilização de públicos; e praticam intensa militância na área musical. ${ }^{17}$

\section{Relevância da Associação Brasileira de Festivais Independentes e do Circuito Fora do Eixo (CFE) reorganizando a cena independente brasileira}

Ainda que a Associação Brasileira de Festivais Independentes (Abrafin) se encontre atualmente extinta, vale a pena destacar a relevância não só desta associação, mas também do Circuito Fora do Eixo (CFE) $)^{18}$ na construção de um circuito e de uma rede nacional de festivais indies, do qual, inclusive, o PP faz parte. Aliás, vale ressaltar que o PP é o único coletivo do Estado do Rio de Janeiro

filiado propriamente ao CFE. ${ }^{19}$

Como já foi assinalado, nesta "retomada atual destes eventos indies", os primeiros festivais de música independente no Brasil começam a surgir nos anos de 1990, período no qual o modelo da indústria fonográfica do século passado começava a dar alguns sinais de desgaste (que seriam mais evidentes no início do século XXI). Na época, estes eventos se tornaram uma das principais alternativas de circulação dos artistas que não eram contemplados pelas grandes gravadoras majors. De fato, estes concertos espalhados por diversos pontos do país desempenharam um importante papel no fortalecimento de cenas locais e regionais (HERSCHMANN, 2013b; STRAW, 2006), além de se constituírem em plataformas para que alguns destes artistas indies alcançassem o grande público. ${ }^{20}$

A consolidação desse circuito indie em diferentes pontos do país culminaria, no final do ano de

Assim, diferentemente dos antigos festivais do século passado e dos grandes festivais e eventos do mainstream atualmente realizados no Brasil - como, por exemplo, SWU e Rock in Rio -, pode-se dizer que os novos festivais independentes: utilizam a mídia alternativa e interativa; os artistas divulgados geralmente não têm vínculos com as majors (ou mesmo pequenas gravadoras); e os eventos se constituem em importantes espaços de consagração e reconhecimento dos músicos dentro do nicho de mercado em que atuam (HERSCHMANN; QUEIROZ, 2012a).

Os atores que trabalham no CFE definem assim o Circuito: "como uma rede que reúne agentes de mais de 100 coletivos espalhados por todas as regiões do país que atuam nos mais variados segmentos culturais, tais como a música, o teatro, 0 circo, a dança, a literatura e 0 audiovisual. Para mais informações, visite: <http://foradoeixo.org.br>. Acesso: 02 jul. 2013.

Há alguns coletivos do Rio de Janeiro que estão no CFE, mas que não parecem ter a mesma consistência de trajetória (como a do PP): é o caso do Norte Comum e Cidadela.

Alguns dos casos mais emblemáticos foram o da banda Los Hermanos e o Abril pro Rock (PE), o da banda Detonautas no Mada (RN) e da banda Planet Hemp com o festival Humaitá pra Peixe (RJ) (HERSCHMANN, 2010b). 
2005, com a fundação da Abrafin. Reunindo

inicialmente 16 produtores dos principais

festivais, a entidade logo triplicou de tamanho, chegando a se constituir em uma importante instância de articulação e diálogo com a iniciativa privada e instituições públicas. Da mesma reunião que deu origem à Abrafin, surgiu também o CFE, originado a partir da articulação de coletivos culturais das cidades de Cuiabá (MT), Londrina (PR), Rio Branco (AC) e Uberlândia (MG). ${ }^{21}$ Como destaca Alves (2013), a proposta inicial consistia em fazer circular o maior número de artistas, privilegiando o intercâmbio de tecnologias sociais e o escoamento de conteúdos culturais fora do eixo Rio-São Paulo. Já o crescimento do CFE foi ainda mais vigoroso: "[...] em março de 2011, 0 circuito já contava com 106 coletivos, sendo seis deles em países latino-americanos".22

Segundo Alves (2013), Corrêa (2012) e Lopes (2012), algumas das principais iniciativas no campo da música independente brasileira do século XXI tiveram a participação ativa da Abrafin. Como ressalta Alves (2013), a entidade desenvolveu importantes iniciativas como, por exemplo: a) exerceu um papel relevante no reconhecimento da importância dos editais de incentivo à cultura, participando dos que foram lançados nos últimos anos por importantes instituições, tais como 0 da Petrobras e Funarte; b) na esfera da política desempenharam um significativo papel na construção de canais de diálogo com o poder público e a sociedade, tais como a criação da Rede Música do Brasil, que se constitui em um canal direto entre 17 entidades representativas do setor da música e 0 Estado; c) e atuaram no Colegiado Setorial da Música, órgão que compõe 0 Conselho Nacional de Políticas Públicas - instância importante de elaboração do atual Plano Nacional de Cultural do país. Além disso, vale salientar que, durante seus anos de existência, esta associação manteve um nível de crescimento elevado dos seus eventos, demonstrando grande capacidade de mobilização dos atores e dos coletivos associados, chegando a reunir aproximadamente 45 festivais no seu último ano de existência. ${ }^{23}$

Pablo Capilé, um dos principais articuladores e forte liderança do CFE, explica, em entrevista concedida a Sergio Cohn, 0 início destas duas entidades: "[...] os pequenos festivais trocavam no varejo, os pequenos empreendedores trocavam no varejo e, em 2005, veio uma consciência da necessidade de começar a se organizar coletivamente [...]. É no fim de 2005 que, numa mesma reunião, surgem a Associação Brasileira de Festivais Independentes e o Circuito Fora do Eixo, um complementar ao outro." (ALVES, 2013).

Para mais detalhes sobre a atuação do CFE na América Latina, consulte: <http://issuu.com/foradoeixo/docs/rela_o_oficial_ de_pontos_fde_2011/1?mode=a_p>. Acesso: 23 abr. 2013.

A Abrafin desmantelou-se em dezembro de 2011, durante a reunião realizada no IV Congresso do Fora do Eixo. Naquela ocasião a gota d'água que levou ao "racha" entre as lideranças e coletivos teria sido a existência de dois projetos políticos diferentes no interior da entidade. Por um lado, os festivais mais antigos e maiores queriam restringir a entrada de novos filiados, exigindo a obrigatoriedade (prevista no estatuto) para filiação na Abrafin da realização de três edições consecutivas de eventos; e, por outro, os festivais vinculados ao CFE queriam ser mais flexíveis à entrada de festivais novos, alegando serem justamente os primeiros anos o período no qual estes empreendedores necessitavam que a entidade os apoiasse. Para mais detalhes sobre a "crise" e a extinção da Abrafin, consulte Alves (2013). 
A trajetória do CFE é igualmente meteórica e também fundamental para o desenvolvimento da cena independente atual do país. Esta rede de coletivos continua ativa até hoje e surgiu com a proposta de reunir grupos independentes, oriundos de áreas "periféricas" do país e, efetivamente, depois de alguns anos, pode-se dizer que vem realizando um dos mais interessantes e inovadores trabalhos dentro do cenário cultural brasileiro. Essa rede vem realizando uma série de experiências - a grande maioria - bem-sucedidas no setor da música, especialmente envolvendo a música ao vivo. Dessas experiências acumuladas, desenvolveram uma metodologia e passaram a compartilhá-la com outros grupos de outras cidades. Aliás, a principal estratégia dessa rede foi a de buscar trabalhar de forma sinérgica para fomentar a criação de oportunidades para as bandas (especialmente através dos festivais) e trocar experiências para inovar a produção e a gestão da música.

Segundo Yúdice (2011), o CFE tem mais de 73 unidades espalhadas em todos os estados do país e atuam ainda em diversos países da América Latina. Os eventos mais importantes que realizam são: 0 Grito Rock (na América do Sul) e o Fora do Eixo Festival, além dos congressos (do Fora do Eixo). Além disso, construíram não só um centro de pesquisas (o Observatório Fora do Eixo), mas também um escritório em São Paulo, que nomearam de Fora do Eixo no Eixo, a partir do qual coordenam todas as atividades desta rede de coletivos ou "rede das redes" (FERNANDES, 2009). Mais de quinhentas pessoas trabalham no
CFE para garantir a sustentabilidade dessa rede alternativa de produção e gestão. Todas as suas atividades e arquivos, inclusive os que tratam de suas finanças, são disponibilizados na internet para garantir a transparência, usando software de open source. Agustini (2009) salienta que Capilé considera o CFE como uma grande rede de coletivos que trocam tecnologias e investem na economia do conhecimento, criando ferramentas e processos que visam facilitar a difusão de produtos culturais e o engajamento de mais atores (como força politica).

Como salienta Yúdice (2011, p. 41), se, por um lado, a atuação do CFE é dinâmica e digna de elogios, por outro, não está livre de controvérsias:

[...] as lideranças do CFE estão firmes no seu propósito de usar todos os recursos para expandir a capacidade da rede de criar eventos e iniciativas (baseado nos princípios de modelo de negócio aberto e na economia solidária). [...] alguns músicos sentem-se prejudicados, pois quase sempre $0 \mathrm{CFE}$ não paga em reais pela apresentação nos festivais (utiliza basicamente as moedas complementares) [...] embora seus eventos sejam financiados em parte com recursos públicos. Capilé explica que o propósito principal dos festivais é apresentar as bandas e formar públicos. Segundo ele, os fundos que 0 CFE utiliza são investidos em infraestrutura para tornar essas funções possíveis. [...] [Além disso, na avaliação de Capilé] 0 grande número de bandas que viajam para os festivais espalhados pelas regiões Norte e Centro Oeste do país em geral não gera bilheteria suficiente para bancar todas as despesas. Outro ponto controverso é 0 uso das licenças creative commons, que permitem que fonogramas dos artistas sejam apropriados e agenciados de diferentes maneiras pela rede. Em recentes debates, houve críticas 
a intensa institucionalização do CFE, sobretudo a sua participação em editais para verbas públicas e as alianças construídas com o poder público. Essas críticas vêm de pessoas que acham que o CFE esta perdendo sua dimensão utópica [...]. [Yúdice argumenta que] [...] essa institucionalização é necessária para ter ainda mais incidência na reestruturação dos circuitos de oportunidade para a atividade cultural. 0 interessante do CFE é que são ao mesmo tempo utópicos e pragmáticos [...]. Poder-se-ia dizer que o CFE é na verdade um amplo, ousado e diversificado movimento sociocultural.

Ainda que não deem conta inteiramente do grande desafio da sustentabilidade para artistas independentes do país e a despeito de qualquer crítica que se possa fazer a atuação da Abrafin e especialmente ao CFE: é inegável que a maioria das áreas (algumas bem remotas) - que anteriormente não possuíam atividades musicais e culturais (localizadas no interior do Brasil e fora do eixo Rio-São Paulo) - só passou a contar com alguns patamares de "vida cultural" e até um calendário anual de eventos (ainda que bastante precário), por conta da atuação em rede e significativa de ambos, neste início de século XXI.

\section{Consolidação de uma cena independente em Niterói: entre a construção de um "polo de música" e a construção de um "nó da rede de redes"}

Apresenta-se a seguir uma breve análise comparativa da trajetória e atuação do AR e do
PP nos seus respectivos intentos de desenvolver a chamada cena indie de Niterói.

\subsection{Araribóia Rock}

Analisando as informações coletadas sobre a trajetória do AR, é preciso salientar que durante algum tempo - mais precisamente entre 2004 e 2009 - o coletivo AR aglutinou e articulou as iniciativas da cena roqueira local. Contudo, 0 projeto do "polo alternativo" permanece ainda como uma meta inalcançável e distante.

Fundado por importantes lideranças como Pedro de Luna, Maurício Machado e Marcelo Blau Blau, como outros coletivos da atualidade, vem empregando as ferramentas disponibilizadas pelas novas tecnologias de comunicação para se relacionar com sua rede de membros (produtores e fãs), isto é, esta rede vem realizando suas articulações especialmente através de $e$-mails, blogs e, mais recentemente, através do Facebook. ${ }^{24}$ Durante algum tempo um grande número de bandas - cerca de sessenta grupos, a maioria de Niterói e São Gonçalo - estiveram filiados ao AR. Bandas como Starlla, Prosaico e Tijolo de Vera, Bendis, The Feitos, Seu Miranda, Filhos do Totem, Bleach e Noitibó oriundas dessas localidades e que são bastante conhecidas entre as redes sociais locais movimentaram um público expressivo e permitiram que as iniciativas do 
AR durante algum tempo gerassem significativa repercussão na grande mídia. ${ }^{25}$ Ao longo dos seus oito anos de existência, basicamente $0 \mathrm{AR}$ se dedicou a realização de seu festival anual: que leva o nome do coletivo e sempre foi realizado em Niterói e adjacências. ${ }^{26}$ Além disso, articulou-se a casas de espetáculo e bares bastante conhecidos na região de Niterói e São Gonçalo, tais como Convés, Bar do Blues, Arabs Café, Aldeia Velha e Tribos da Cantareira, em algum momento, já dedicaram boa parte da sua programação aos concertos e eventos organizados pelo AR (LUNA, 2011).

Segundo seu principal articulador, Pedro de Luna (informação verbal), ${ }^{27} 0 \mathrm{AR}$ foi criado oficialmente em dezembro de 2004 e se inspirou no trabalho que vinha sendo feito na Abrafin e pelo CFE:

[...] tinha viajado nessa época para Cuiabá e conhecido o pessoal da Abrafin e do CFE: cheguei de lá com essa ideia de coletivo e de movimento social na cabeça. Fizemos algumas reuniões com importantes lideranças da época. Claro que nos inspiramos também no Mangue Beat, que também é uma experiência clássica do underground da música. Então essa foi a nossa expectativa... Assim nos organizamos, criamos uma logomarca e tentamos mobilizar intensamente as bandas de rock. Pedimos que as bandas e produtores de eventos de rock local sempre que tivessem alguma coisa colocassem o nome do AR. Fizemos muito barulho e depois de algum tempo o pessoal começou a acreditar no nosso movimento sociocultural na cidade. Ao mesmo tempo começou a se criar uma unidade e o coletivo começou a crescer, porém de forma meio descentralizada porque 0 Araribóia Rock nunca teve sede, nunca teve exatamente um escritório. Sempre tivemos um sonho e a internet para nos auxiliar a mobilizar as pessoas.

Apesar de ter tido sempre uma atuação destacada na região de Niterói (e arredores) - que redundou em parcerias e articulações importantes com entidades e o poder público local, tais como o Sebrae-RJ, Secretaria de Cultura de Niterói, SESC-RJ, Conselho Municipal de Cultura e a Universidade Federal Fluminense - pelo que se pode atestar durante a pesquisa (nos depoimentos colhidos e analisando o blog e Facebook do $\mathrm{AR}$ ), a principal bandeira deste coletivo é principalmente a "luta por mais espaço para 0 rock independente $n a$ e $d a$ cidade de Niterói" (e da cidade de São Gonçalo também: cidade satélite de Niterói que concentra algumas bandas e frequentadores locais). ${ }^{28}$ Uma das

Cf. algumas das matérias sobre o AR que saíram em jornais de grande circulação: Frade(2012), Redação... (2011), Albuquerque e Leão(2011) e Redação... (2006).

26 Outra realização importante deste coletivo é o Dia Mundial do Rock, comemorado anualmente no dia 13 de julho (cf. https://www.facebook.com/ArariboiaRockPage?fref=ts).

Entrevista concedida ao autor no dia 20 de janeiro de 2010.

Ainda que se pudessem constatar na pesquisa algumas exceções, geralmente 0 AR tem trabalhado com artistas que moram em Niterói e São Gonçalo, os quais privilegiam no seu cardápio musical o rock como gênero musical central. 
estratégias que o AR pretendia empregar, mas que praticamente não se concretizou - com exceção de alguns discos lançados - foi a ideia de criação de um "selo territorial" (de Niterói e de São Gonçalo). Ainda que esta inciativa não tenha se concretizado, ${ }^{29}$ ela é reveladora do tipo de linha de atuação desse coletivo. Segundo Pedro de Luna ${ }^{30}$

[...] o AR vem buscando atingir resultados concretos, mostrando a qualidade das bandas, buscando oferecer a elas algum retorno. Assim, a criação de novos selos locais [...] é importante. Além disso, avaliamos também a criação de um selo Araribóia Discos também.

Assim, o AR apesar de ter sido bastante atuante na localidade - especialmente nos primeiros anos da sua trajetória - nunca conseguiu se articular inteiramente e de forma profícua com a Abrafin e nem com 0 CFE, adotando de certo modo uma "postura localista meio radical", na tentativa de construir um polo alternativo de música à cidade que é considerada uma espécie de principal "celeiro musical" do país. Este conjunto de estratégias teve duas consequências com desdobramentos paradoxais e que explica em alguma medida a trajetória do AR: se, por um lado, em alguns momentos o público composto basicamente de moradores de Niterói e São Gonçalo se sentia plenamente identificado "comprando" a ideia de "autenticidade", de uma "tradição roqueira bairrista" da localidade ${ }^{31} \mathrm{e}$ impelido a participar das atividades promovidas pelo coletivo; por outro lado, ao adotar esses parâmetros de atuação, o AR sempre esteve limitado a um engajamento identitário do tipo moderno e conservador (HALL, 1997) e ao cast de artistas filiados, portanto, tinha "pouca munição à sua disposição (seu leque de artistas e bandas sempre foi restrito)" e capacidade de mobilizar com alguma frequência diferentes tipos de "neotribos" (MAFFESOLI, 1987), as quais estão habituadas a consumir rock e estão (de modo geral) caracterizadas por um intenso nomadismo (e, portanto, estão em geral dispostas a vir de outras localidades e centros urbanos próximos como, por exemplo, o Rio de Janeiro

Por conta da transição (e reestruturação) da indústria da música em curso neste início de século XXI (HERSCHMANN, 2010a), que afetou também as pequenas gravadoras e selos independentes (ampliando o receio desses empreendedores em investir em novos talentos, em projetos mais arriscados), esta iniciativa não conseguiu ser levada adiante.

Revela também uma preocupação um tanto excessiva do AR com o status da gravação dos fonogramas, que foi epicentro do modelo de indústria da música do século XX, mas que hoje está sendo redimensionada: especialmente com a crescente popularidade não só da lógica do compartilhamento livre de arquivos (de som e imagem), mas também da música ao vivo uma crise profunda (HERSCHMANN, 2010a).

É interessante notar nos discursos colhidos entre os atores desta cena - os quais constroem a "tradição roqueira de Niterói" - que há a evocação frequente a trajetória da celebrada Radio Fluminense FM (conhecida como "a maldita" e com a programação praticamente toda dedicada ao gênero do rock) e a trajetória de alguns músicos locais (que ganharam notoriedade e que trabalham com música instrumental e rock), tais como Arthur Maia, Claudio Zoli e a banda Los Locos. A respeito dos processos de (re) construções das tradições consulte Ranger e; Hobsbawn (1984). 
e adjacências). Pelo que se pode atestar nos

depoimentos concedidos pelos frequentadores

desta cena musical local, o AR encontra-se

atualmente vivendo certa "crise" por conta

das limitações impostas pelas suas próprias

estratégias atuação. Luna, principal liderança

deste coletivo, reconhece a necessidade de rever

as suas diretrizes de atuação do AR:

[...] [Nosso público deve] [...] ter estranhado 0 sumiço do AR depois do festival de comemoração dos seus oito anos de existência, mas é que 2012 foi um ano de aprendizados. Agora, corrigindo rumos, vamos mudar radicalmente a forma de gestão do coletivo. [...] Portanto, após quase uma década e centenas de shows realizados, o AR se prepara para corrigir os rumos [...] (Postado por Pedro de Luna, no dia 02 de abril de 2013, na página do Facebook do AR).

\subsection{Ponte Plural}

Vale a pena sublinhar que 0 PP foi criado em 2010, de uma dissidência do AR, capitaneada pelos seus atuais coordenadores e líderes, Daniel Domingues e Luiza Bittencourt. ${ }^{32}$ Ao longo desses três anos de existência, o PP tem se notabilizado como um dos coletivos mais dinâmicos do país, com grande preocupação em realizar um trabalho de formação e capacitação no Estado do Rio de Janeiro. ${ }^{33}$ Evidentemente, como outros coletivos do CFE, ficaram muito conhecidos por conta da organização e realização de importantes festivais. Aliás, com certa regularidade, o PP vem organizando os seguintes festivais independentes: Grito Rock (edição do RJ), ${ }^{34}$ Fora do Eixo ${ }^{35} \mathrm{e}$ Festival Musical Mente Plural ${ }^{36}$

32 Por desejarem trabalhar com o pessoal do CFE (com quem Pedro de Luna tinha discordâncias significativas) e dentro de uma perspectiva menos restrita a um território (isto é, não só ancorada na localidade de Niterói e de São Gonçalo) em 2009, os coordenadores "[...] resolveram sair do AR e fundar um novo coletivo" (Entrevista concedida a esta pesquisa por Luiza Bittencourt, liderança do PP, em 19 de julho de 2010).

Segundo Daniel Domingues, o PP vem realizando com grande êxito o projeto Músico Plural, com oficinas e workshop para capacitação e gestão de carreira de músicos do Estado do Rio de Janeiro. Essas oficinas já foram realizadas em diversas cidades do estado (Entrevista concedida ao autor por Daniel Domingues, liderança do PP, no dia 01 de julho de 2013).

Realizado há dez anos no Brasil, em 2012 o Festival Grito Rock chegou à marca de 200 cidades participantes, em 10 países. 0 PP assumiu a produção do evento no Estado do Rio de Janeiro em 2010, quando o festival ganhou uma nova casa: o Circo Voador, na Lapa. No mesmo ano, o coletivo produziu a primeira edição em Niterói. Desde então vem realizando a curadoria e produção do evento em mais de uma dezena de cidades no Rio de Janeiro. Visite a página do PP: <www.ponteplural.com.br >. Acesso: 12 jun. 2013.

Em 2012 foi realizada a $3^{a}$ edição do Festival Fora do Eixo país nas cidades do Rio de Janeiro, Niterói e Nova Friburgo: com shows, oficinas, mostra de artes visuais, cênicas e de literatura e reunindo artistas das cinco regiões do país. Cabe destacar ainda que, em 2011, este evento foi contemplado pelo edital de fomento a festivais, da Secretaria Estadual de Cultura do Estado do RJ e atingiu mais 4 mil pessoas. Para mais informações acesse: <www.ponteplural.com.br >. Acesso: 12 jun. 2013.

Realizado em parceria entre o coletivo Ponte Plural e a Musical Mente, produtora formada por alunos do curso de Produção Cultural da Universidade Federal Fluminense. Foram realizadas duas edições do evento nos campi da UFF, que reuniram cerca de 10.000 pessoas. Com entrada gratuita, o festival apresentou shows, oficinas, mostra de filmes e palestras. Para mais detalhes acesse: <www.ponteplural.com.br >. Acesso: 12 jun. 2013 
Analisando as iniciativas e os eventos do PP chama a atenção o fato do coletivo não só atuar de forma nômade pelo Brasil afora, mas seguir investindo em eventos na cidade de Niterói e em outras cidades menores do Estado do Rio Janeiro, reproduzindo em alguma medida a estratégia dos coletivos do CFE (que buscam ampliar a vida musical e cultural de localidades do interior ou fora das grandes capitais). Aliás, o Festival Fora do Eixo, organizado pelo PP na cidade do Rio, Niterói e Nova Friburgo vem sendo considerado pelos críticos (inclusive pelos que trabalham na mídia tradicional) como o melhor festival indie do Estado do Rio de Janeiro das últimas décadas. Vale ressaltar que, de modo geral, este coletivo realizou dezenas de eventos e festivais gratuitos ou a preços populares com circulação de mais de 200 artistas de todas as regiões do país, atingindo um público de mais de 30 mil pessoas, especialmente em seis cidades do Estado do Rio de Janeiro: Niterói, Nova Friburgo, Cordeiro, Três Rios, Volta Redonda e, evidentemente, a cidade do Rio.

Trabalhando muito intensamente com grupos de artistas bastante conhecidos na nova cena musical nacional, tais como Teatro Mágico, Tereza, Macaco Bong e Móveis Coloniais, o PP vem realizando concertos em algumas das principais casas de espetáculo indie do eixo Rio-São Paulo, tais como: Studio RJ, Circo Voador, Studio SP e Studio Vila (os dois últimos espaços, localizados na cidade de São Paulo, atualmente encontram-se fechados). Sem dúvida, a principal atividade do PP em casas noturnas, é a mostra Cedo e Sentado Fora do Eixo, atualmente renomeada como Noites do Fora do Eixo, realizada no Studio RJ. ${ }^{37}$

Diferentemente do AR, o PP optou por não trabalhar com uma lógica de pertencimento ou até "exclusivista" (como as gravadoras e intermediários da indústria da música faziam no século XX): os músicos podem trabalhar com o PP em diferentes níveis, seja através de ações mais pontuais (em geral, para articular a participação em eventos e concertos avulsos) ou em "projetos" que tendem durar um pouco mais (e que podem envolver trabalho de capacitação e gestão do trabalho musical, elaboração e promoção de um álbum, etc.).

Algumas pessoas questionam muitas coisas do CFE, mas 0 fato é que várias das propostas colocadas em prática pelo CFE funcionam muito bem. É impressionante a dedicação das pessoas envolvidas. [...] É preciso rebeldia, mas também tato e um pouco de objetividade. Não adianta você ficar numa postura rebelde, fazendo manifestos e só falando mal. Na verdade não é isso que vai fazer mudar a forma de se fazer política pública cultural neste país. $0 \mathrm{PP}$ e os coletivos do CFE trabalham de forma bem diferente do AR. No AR basta você ser uma banda de Niterói ou de São Gonçalo para ser considerado como parte 
deste coletivo (preenchendo apenas um cadastro por e-mail). De que adianta isso? Você pode ter duzentas bandas cadastradas, mas que na prática não se articulam entre elas e com 0 coletivo. A sensação que se tem é que mal sabem porque fizeram aquele cadastro, sabe? Optamos por trabalhar com bandas que perceberam que o negócio da música mudou. As bandas que trabalham com o PP toparam entrar no circuito dos festivais do CFE e enfrentaram várias dificuldades e foram favorecidas pelas colaborações das redes de coletivos também [...]. E, ao tempo, contaram com todo nosso apoio [...]. Vários artistas já estão colhendo resultados $[\ldots] .{ }^{38}$

Assim como 0 AR, o PP vem utilizando novas tecnologias de comunicação para se articular com sua rede de artistas e fãs (isto é, vem mobilizando sua rede especialmente através de mensagens e conteúdos veiculados em blogs e, mais recentemente, através do Facebook). Entretanto, o que chama a atenção é que o PP utiliza a plataforma do CFE de forma integrada, caracterizando suas iniciativas como parte de uma rede maior (articulada ao CFE). Portanto, procuram postar muito material audiovisual com entrevistas e concertos dos integrantes que participam dos coletivos do CFE. Durante a pesquisa, inclusive, anunciaram que estão tentando veicular conteúdos através de trabalhos de webtv e de webradio. Além disso, a equipe do PP vem demonstrando grande capacidade de articulação e de "tato" com o institucional. Não só participam de articulações com o Conselho Municipal de Niterói, a UFF e a Secretaria Municipal de Cultura de Niterói (como o coletivo AR), mas também se articulam com instituições e entidades de outras localidades, tais como: Secretaria de Cultura do Estado do Rio de Janeiro, Sebrae-RJ (Projeto Estrombo), UFRJ, SESC-RJ, FGV, entre outros. ${ }^{39}$

Assim, 0 fato estarem integrados às redes do CFE, permitiu que acumulasse considerável "capital simbólico" (BOURDIEU, 1983) e isso foi importante para que o PP se destacasse na cena independente nacional. Mas não foi só isso: 0

Entrevista concedida ao autor por Daniel Domingues, liderança do PP, no dia 19 de julho de 2010.

Em 2010, após efetuar um mapeamento de agentes culturais no Estado do Rio de Janeiro, o coletivo deu início à organização da "Rio Arte Independente", rede estadual de cultura do Estado do RJ, através da qual foi possível efetuar o Festival Grito Rock 2011 em vinte cidades da região, além de outras ações de intercâmbio de artistas e de capacitação que movimentaram centenas de pessoas. Em 2010 e 2011 teve dois projetos contemplados no edital de fomento a Festivais da SEC/RJ; cinco projetos tiveram a captação aprovada através da Lei do ICMS; obteve aprovação do projeto de capacitação Músico Plural no edital de Microprojetos Culturais e no edital do Circuito Estadual das Artes, quando realizou a circulação da banda brasiliense Móveis Coloniais de Acaju em shows gratuitos em 3 cidades do interior do Estado. Na área de capacitação, o Ponte Plural realizou uma série de palestras sobre novos canais de distribuição da música em parceria com o projeto Estrombo, desenvolvido pelo Sebrae/RJ, Banco Interamericano de Desenvolvimento e a Fundação Getúlio Vargas. Além disso, o PP organizou palestras na Universidade Federal Fluminense, oficinas de elaboração projetos e de desenvolvimento de selos no Centro Calouste Gulbenkian e participou de debates no SESC, na UFRJ, tornou-se referência na área acadêmica, tem sido objeto de estudo de dissertações e foi convidada para um seminário na Espanha para apresentação de seu case. Atualmente, o coletivo iniciou uma circulação por cidades do interior do estado apresentando o workshop Músico Plural, que fornece noções empreendedoras para autogestão de carreiras musicais. Em 2011, a Ponte Plural foi um dos empreendimentos culturais selecionados pela Secretaria Estadual de Cultura para integrar o Rio Criativo, a primeira incubadora com foco em economia criativa do Estado. Para mais informações consulte: <www.ponteplural.com.br >. Acesso: 12 jun. 2013. 
êxito deste coletivo é em alguma medida explicado também pela qualificação dos profissionais que ali trabalham. Cabe destacar que a equipe do $\mathrm{PP}^{40}$ é altamente qualificada, pois não só vem participando da maioria dos eventos e congressos do CFE dos últimos anos - durante os quais há muito espaço dedicado a palestras e intercâmbio entre os atores que atuam na cena indie (espaços inclusive para que alguns especialistas - do meio acadêmico - ministrem palestras nos encontros) ,- mas também porque a grande maioria vem realizando um trabalho de formação continuada, isto é, quase todos realizaram ou vem realizando cursos de pós-graduação de latu e/ou strictu sensu.

\section{Considerações finais}

Como se pode constatar no material e argumentos apresentados e analisados aqui, há uma "aposta" em lógicas e/ou estratégias bastante distintas para a consolidação de uma cena musical (roqueira) em Niterói. Por um lado, atestou-se que o AR claramente investiu na tentativa constante de formar um polo alternativo ao Rio; e por outro, 0 PP "jogou as sua fichas" nas sinergias resultantes do intercâmbio entre artistas e produtores de diferentes localidades do país, na participação em redes de coletivos que atuam em diferentes escalas (que variam do local ao transnacional).

A esta altura, poder-se-ia indagar se há efetivamente uma cena musical independente em Niterói. Ainda que este não seja o objetivo deste artigo (que se dedica mais especificamente não a julgar, mas a analisar as estratégias desenvolvidas pelo AR e PP, especialmente nos últimos anos) e 0 fato do trabalho vir sendo realizado de forma ainda bastante recente 0 que dificulta qualquer avaliação (os coletivos analisados vem atuando há menos de uma década na localidade), poder-se-ia afirmar que inúmeras dificuldades persistem, ${ }^{41}$ mas constata-se que as estratégias inovadoras desenvolvidas de forma a usar as sinergias de redes de coletivos independentes que estão vinculados ao CFE - adotadas pelo PP abrem novas perspectivas para se dinamizar uma cena indie em Niterói, não só desterritorializando esta região - descolando-a da proximidade e do "brilho ofuscante" da "cidade maravilhosa" -, mas também reterritorializando esta urbe como uma espacialidade atraente,

Em seu site oficial, o PP apresenta-se como um coletivo de empreendedores culturais de diferentes áreas (audiovisual, música, mídias, rádio e jornalismo), formado em março de 2010, que tem como objetivo fomentar a cena cultural do Estado do Rio de Janeiro, promovendo a disseminação da produção regional. Além de Daniel Domingues e Luiza Bittencourt, que são coordenadores do coletivo, participam ainda do PP: Rafael Lage, Bianca Freire e Natalia Dias. Ainda no site, este coletivo informa que quer ser "um ponto de articulação no Rio de Janeiro do Circuito Fora do Eixo". Para mais detalhes, consulte: <www.ponteplural.com.br>. Acesso: 12 jun. 2013.

Em outro artigo, desenvolvido em parceria com Fernandes, chegou a se listar alguns aspectos que seriam importantes para que uma cena musical tenha capacidade de se reproduzir: a) espaços significativos para os gêneros musicais e os atores envolvidos na mídia tradicional; b) existência de blogosfera e redes sociais dando visibilidade as iniciativas da cena; c) realização de concertos na rua e/ou em casas de espetáculo; d) para além dos concertos, a existência de espaços para trocas interpessoais onde manifestam sociabilidades e afetos; e) presença de uma produção fonográfica regular; f) interesse da critica e do jornalismo cultural na sua divulgação; g) e a estruturação de circuitos de festivais e eventos (HERSCHMANN e FERNANDES, 2012c). 
ou melhor, como uma "territorialidade sônicomusical" com algum potencial de mobilização (HERSCHMANN; FERNANDES, 2012b). ${ }^{42}$

Justamente por não se aterem apenas ao espaço de Niterói (aspecto que, às vezes, não é muito bem compreendido pelos frequentadores mais conservadores), o PP e seus artistas abrem um novo leque de possibilidades: por um lado, podem capitalizar com o intercâmbio entre os atores; e, por outro, não só podem atrair os olhares da mídia tradicional e alternativa e, assim, adquirir mais visibilidade, mas também podem conseguir ampliar seu nicho de mercado e/ou redes de fãs. Em resumo, o PP dribla as tensões, rivalidades e bairrismos entre Rio e Niterói e abre caminho para a construção de uma "territorialidade sônicomusical" (HERSCHMANN; FERNANDES, 2012b) que pode emergir de forma mais sistemática no local e, assim, alicerçar a estruturação de uma cena musical independente do lado menos conhecido da Baía de Guanabara.

\section{Referências}

ALBUQUERQUE, C. A geração 2010. 0 Globo. Rio de Janeiro, 31 maio 2013, Segundo Caderno, p. 1. Disponível em: < http://oglobo.globo.com/cultura/apolloopala-mahmundi-sao-alguns-dos-nomes-do-novo-somque-embala-rio-8546919> . Acesso em: 20 jul. 2013.

ALBUQUERQUE, C. Na trilha dos sem voz. 0 Globo. Rio de Janeiro, 10 jul. 2011. Segundo Caderno.

ALBUQUERQUE, C.; LEÃO, T. 0 rock de Niterói documentado. 0 Globo. Rio de Janeiro, 13 jul. 2011.

\section{ALVES, T. M. Os festivais de música independente} no capitalismo cognitivo. Rio de Janeiro: Dissertação (Mestrado em Comunicação) - Universidade Federal do Rio de Janeiro, 2013.

ANDERSON, C. A cauda longa. São Paulo: Campus, 2007.

AGUSTINI, G. Circuito fora do eixo: a economia do conhecimento em rede. In: SEMINÁRIO INTERNACIONAL DO FÓRUM DA CULTURA DIGITAL BRASILEIRA. Salvador, 2009. Disponível em: < http:// culturadigital.br/seminariointernacional/2009/12/15/ circuito-fora-do-eixo > . Acesso em: 02 fev. 2013.

L0 BIANC0, A. Festival do Fora do Eixo na Praia de Icaraí. 0 Globo, Rio de Janeiro, 08 dez. 2012. Disponível em: < http://oglobo.globo.com/niteroi/ festival-fora-do-eixo-na-praia-de-icarai-6974445>. Acesso em: 08 abr. 2013.

BOURDIEU, P. Questões de sociologia. Rio de Janeiro: Marco Zero, 1983.

\section{CORREAA, W. Produção, comunicação e consumo} musical no Brasil no início do século XXI. Rio de Janeiro: Dissertação (Mestrado em Comunicação) Universidade Federal do Rio de Janeiro, 2012.

DE LUNA, P. Niterói rock underground (1990-2010). Rio de Janeiro: [s.n.], 2011.

DIAS, P. É como a banda toca. 0 Globo. Rio de Janeiro, 13 jan. 2011. Caderno Boa Chance.

FERNANDES, C.a S. Sociabilidade, comunicação e política. Rio de Janeiro: E-Papers, 2009.

FLAVIO JÚNIOR, J. A nova era dos festivais. Bravo. São Paulo, maio, 2009. Disponível em: < bravonline.abril. com.br/conteudo/musica/nova-era-festivais-467150. shtml>. Acesso em: 10 maio 2010.

FRADE, T. Oitava edição do Araribóia Rock celebra o cenário alternativo. 0 Globo. Rio de Janeiro,

Capaz de se constituir em um "nó ou ponto da rede" de coletivos indies, os quais estão organizados de forma colaborativa e que circulam em fluxo contínuo. 
01 dez. 2012, p. 5, Caderno Rio. (disponível em:

$<$ http://oglobo.globo.com/bairros/oitava-edicao-

do-arariboia-rock-celebra-cenario-alternativo-

6889056\#ixzz2XKmqLAmS >. Acesso: 24 jun. 2013).

FREIRE FILHO, J. 0 rock está morto, viva 0 rap!

Revista Ícone. Recife, v. 1, n. 6, out. 2003, pp.134-157.

HALL, S. Identidades culturais na pós-modernidade. Rio de Janeiro: DP\&A Ed., 1997.

HERSCHMANN, M. A indústria da música em

transição. São Paulo: Editora Estação das Letras e das Cores, 2010a.

HERSCHMANN, M. Crescimento dos festivais de música independente no Brasil. In: SÁ, Simone P. (org.). Rumos da cultura da música. Porto Alegre: Sulinas, 2010b. p. 267-304.

HERSCHMANN, M. (Org.). Nas bordas e fora do mainstream musical. São Paulo: Editora Estação das Letras e das Cores, 2011.

HERSCHMANN, M. Carência de dados e desafios metodológicos para o desenvolvimento dos estudos da indústria da música. In: Famecos. Porto Alegre: PPGC0M da PUC-RS, v. 20, n. 1, pp. 131-146, 2013 a. Disponível em: < http://revistaseletronicas.pucrs.br/ojs/ index.php/revistafamecos/article/view/13129/9203> . Acesso em: 14 jun. 2013.

HERSCHMANN, M. Cenas, Circuitos e territorialidades sônico-musicais. In: JANOTTI JUNIOR, J.; SÁ, S. P. de (Org.). Cenas Musicais. Guararema: Anadarco, 2013b. HERSCHMANN, M; QUEIROZ, T. Balanço da experiência sonora e lúdica da edição 2011 do Rock in Rio. In: FERNANDES, C. S. et al. (Org.) Comunicações e territorialidades: Rio de Janeiro em Cena. Rio de Janeiro: Anadarco, 2012a.

HERSCHMANN, M.; FERNANDES, C. S. Potencial movente do espetáculo, da música e da espacialidade no Rio de Janeiro. In: RIBEIR0, A. P. G.; FREIRE FILHO, J.; HERSCHMANN, M. (Org.) Entretenimento,
Felicidade e Memória: forças moventes do contemporâneo. Rio de Janeiro: Anadarco, 2012b.

HERSCHMANN, M.; FERNANDES, C. S. Nova Orleans não é aqui? E-Compós. Brasília: Compós, v. 15, n. 2, 2012c.

HOBSBAWM, E.; RANGER, T. A invenção das

tradições. Rio de Janeiro: Paz e Terra, 1984.

HOMEM DE MEL0, Z. A era dos festivais. São Paulo: Ed. 34, 2003.

JENKINS, H. Cultura da convergência. São Paulo: Aleph, 2008.

LOPES, T. ABRAFIN 2.0. Pagina Central. Jun. 2012. (disponível em: < http://paginacentral.com.br/cinema/ abrafin-2-0>. Acesso em: 12 maio 2013).

LUZ, M. da. Políticas culturais e intervenções urbanas em Niterói: o caminho Niemeyer. In: ENCONTR0 ANUAL DA ANPOCS. In: Anais da 32 ${ }^{\mathrm{a}}$ ANPOCS. Caxambu: ANPOCS, 2008.

MAFFESOLI, M. 0 ritmo da vida. Rio de Janeiro: Record, 2007.

MAFFESOLI, M. 0 tempo das tribos. Rio de Janeiro: Forense-Universitária, 1987.

NAPOLITANO, M. Engajamento político e indústria cultural na MPB (1959-1969). São Paulo: Annablume, 2001.

PINE, B. J.; GILMORE, J. 0 espetáculo dos negócios. Rio de Janeiro: Campus, 2001.

REDAÇÃO. Cultura Alternativa. 0 Globo. Rio de Janeiro, 10 jul. 2011, Caderno Zona Norte.

REDAÇÃO. Um por todos e todos por um. 0 Globo. Rio de Janeiro, 23 jan. 2006. Niterói.

RIBEIR0, S. Prepare seu coração. São Paulo: Ed. Geração Editorial, 2002.

STRAW, W. Systems of articulation, logics of change: communities and scenes in popular music. Cultural

Studies. Londres: Routledge, v. 5, n. 3, p. 87-102, out. 1991. 
STRAW, W. Scenes and sensibilities. E-Compós,

Brasília, v. 6, p. 1-16, ago. 2006. Disponível em: < http://

www.compos.org.br/seer/index.php/e-compos/article/

view/83/83 > . Acesso: 10 jan. 2013.

VILARINO, R. A MPB em movimento. São Paulo: Olho d'água, 1999.

YÚDICE, G. Apontamentos sobre alguns dos novos negócios da música. In: HERSCHMANN, M. (Org.). Nas bordas e fora do mainstream musical. São Paulo:

Editora Estação das Letras e das Cores, 2011. 
Building an independent music scene in Niterói at the beginning of XXI century: the case study of collectives Araribóia Rock and Ponte Plural

\section{Abstract}

Referring not only the works of leading experts as Straw, Yúdice, Jenkins and Maffesoli, but also the empirical research conducted between 2010 and 2013 - research built from the collection, selection and analysis of articles published in traditional print media and material posted in social networks, field observations and semi-structured interviews with social actors (producers, musicians and fans/consumers) - we tried to take stock of the challenges and prospects (especially in the last two decades) to develop an independent music scene in the city of Niterói.

\section{Keywords}

Communication, Urban Culture, Music Scenes, Independent Festivals.
La construcción de una escena de la música independiente en Niterói a principios del siglo XXI: el estudio de caso de los colectivos Araribóia Rock y Ponte Plural

\section{Resumen}

Trabajando no sólo con las obras de destacados expertos tales como Yúdice, Jenkins y Maffesoli, sino también a partir de la investigación empírica llevada a cabo entre 2010 y 2013 -la investigación organizada a partir de la recopilación, selección y análisis de los enunciados que transmiten en los medios impresos tradicionales y el material publicado en las redes sociales, las observaciones de campo y entrevistas con actores sociales (productores, músicos e aficionados/ consumidores)- es que se ha buscado hacer un balance de cuáles son los desafíos y perspectivas (sobre todo en las dos últimas décadas) para desarrollar una escena de la música independiente en la ciudad de Niterói.

\section{Palabras claves}

Comunicación, Cultura Urbana, Escenas Musicales, Festivales Independientes. 


\section{Expediente}

A revista E-Compós é a publicação científica em formato eletrônico da Associação Nacional dos Programas de Pós-Graduação em Comunicação (Compós). Lançada em 2004, tem como principal finalidade difundir a produção acadêmica de pesquisadores da área de Comunicação, inseridos em instituições do Brasil e do exterior.

\section{E-COMPÓS I www.e-compos.org.br I E-ISSN 1808-2599}

Revista da Associação Nacional dos Programas

de Pós-Graduação em Comunicacão.

Brasília, v.17, n.1, jan./abri. 2014.

A identificação das edições, a partir de 2008

passa a ser volume anual com três números.

\section{CONSELHO EDITORIAL}

Afonso Albuquerque, Universidade Federal Fluminense, Brasil Alberto Carlos Augusto Klein, Universidade Estadual de Londrina, Brasil Alex Fernando Teixeira Primo, Universidade Federal do Rio Grande do Sul, Brasil Ana Carolina Damboriarena Escosteguy, Pontifícia Universidade Católica do Rio Grande do Sul, Brasi

Ana Gruszynski, Universidade Federal do Rio Grande do Sul, Brasil Ana Silvia Lopes Davi Médola, Universidade Estadual Paulista, Brasil André Luiz Martins Lemos, Universidade Federal da Bahia, Brasi Ângela Freire Prysthon, Universidade Federal de Pernambuco, Brasil Antônio Fausto Neto, Universidade do Vale do Rio dos Sinos, Brasil Antonio Carlos Hohlfeldt, Pontifícia Universidade Católica do Rio Grande do Sul, Brasil Antonio Roberto Chiachiri Filho, Faculdade Cásper Líbero, Brasi Arlindo Ribeiro Machado, Universidade de São Paulo, Brasil Arthur Autran Franco de Sá Neto, Universidade Federal de São Carlos, Brasil Benjamim Picado, Universidade Federal Fluminense, Brasil César Geraldo Guimarães, Universidade Federal de Minas Gerais, Brasil Cristiane Freitas Gutfreind, Pontifícia Universidade Católica do Rio Grande do Sul, Brasil Denilson Lopes, Universidade Federal do Rio de Janeiro, Brasil Denize Correa Araujo, Universidade Tuiuti do Paraná, Brasi Edilson Cazeloto, Universidade Paulista , Brasil

Eduardo Vicente, Universidade de São Paulo, Brasil Eneus Trindade, Universidade de São Paulo, Brasil Erick Felinto de Oliveira, Universidade do Estado do Rio de Janeiro, Brasi Florence Dravet, Universidade Católica de Brasília, Brasil Gelson Santana, Universidade Anhembi/Morumbi, Brasi Gilson Vieira Monteiro, Universidade Federal do Amazonas, Brasil Gislene da Silva, Universidade Federal de Santa Catarina, Brasil Guillermo Orozco Gómez, Universidad de Guadalajara Gustavo Daudt Fischer, Universidade do Vale do Rio dos Sinos, Brasil Hector Ospina, Universidad de Manizales, Colômbia Herom Vargas, Universidade Municipal de São Caetano do Sul, Brasil Ieda Tucherman, Universidade Federal do Rio de Janeiro, Brasil Inês Vitorino, Universidade Federal do Ceará, Brasil Janice Caiafa, Universidade Federal do Rio de Janeiro, Brasil Jay David Bolter, Georgia Institute of Technology Jeder Silveira Janotti Junior, Universidade Federal de Pernambuco, Brasi João Freire Filho, Universidade Federal do Rio de Janeiro, Brasil John DH Downing, University of Texas at Austin, Estados Unidos
José Afonso da Silva Junior, Universidade Federal de Pernambuco, Brasil José Carlos Rodrigues, Pontifícia Universidade Católica do Rio de Janeiro, Brasil José Luiz Aidar Prado, Pontifícia Universidade Católica de São Paulo, Brasil José Luiz Warren Jardim Gomes Braga, Universidade do Vale do Rio dos Sinos, Brasil Juremir Machado da Silva, Pontifícia Universidade Católica do Rio Grande do Sul, Brasil Laan Mendes Barros, Universidade Metodista de São Paulo, Brasil Lance Strate, Fordham University, USA, Estados Unidos Lorraine Leu, University of Bristol, Grã-Bretanha Lucia Leão, Pontifícia Universidade Católica de São Paulo, Brasil Luciana Panke, Universidade Federal do Paraná, Brasil Luiz Claudio Martino, Universidade de Brasília, Brasil Malena Segura Contrera, Universidade Paulista, Brasil Márcio de Vasconcellos Serelle, Pontifícia Universidade Católica de Minas Gerais, Brasil Maria Aparecida Baccega, Universidade de São Paulo e Escola Superior de Propaganda e Marketing, Brasil Maria das Graças Pinto Coelho, Universidade Federal do Rio Grande do Norte, Brasil Maria Immacolata Vassallo de Lopes, Universidade de São Paulo, Brasil Maria Luiza Martins de Mendonça, Universidade Federal de Goiás, Brasil Mauro de Souza Ventura, Universidade Estadual Paulista, Brasil Mauro Pereira Porto, Tulane University, Estados Unidos Nilda Aparecida Jacks, Universidade Federal do Rio Grande do Sul, Brasil Paulo Roberto Gibaldi Vaz, Universidade Federal do Rio de Janeiro, Brasil Potiguara Mendes Silveira Jr, Universidade Federal de Juiz de Fora, Brasil Renato Cordeiro Gomes, Pontifícia Universidade Católica do Rio de Janeiro, Brasil Robert K Logan, University of Toronto, Canadá

Ronaldo George Helal, Universidade do Estado do Rio de Janeiro, Brasil Rosana de Lima Soares, Universidade de São Paulo, Brasil Rose Melo Rocha, Escola Superior de Propaganda e Marketing, Brasil Rossana Reguillo, Instituto de Estudos Superiores do Ocidente, Mexico Rousiley Celi Moreira Maia, Universidade Federal de Minas Gerais, Brasi Sebastião Carlos de Morais Squirra, Universidade Metodista de São Paulo, Brasil Sebastião Guilherme Albano da Costa, Universidade Federal do Rio Grande do Norte, Brasil

Simone Maria Andrade Pereira de Sá, Universidade Federal Fluminense, Brasi Tiago Quiroga Fausto Neto, Universidade de Brasília, Brasil Suzete Venturelli, Universidade de Brasília, Brasil Valerio Fuenzalida Fernández, Puc-Chile, Chile Veneza Mayora Ronsini, Universidade Federal de Santa Maria, Brasil Vera Regina Veiga França, Universidade Federal de Minas Gerais, Brasil

\section{COMISSÃO EDITORIAL}

Cristiane Freitas Gutfreind I Pontifícia Universidade Católica do Rio Grande do Sul, Brasil Irene Machado I Universidade de São Paulo, Brasil

Jorge Cardoso Filho I Universidade Federal do Reconcavo da Bahia, Brasil / Universidade Federal da Bahia, Brasil

CONSULTORES AD HOC

Adriana Amaral, Universidade do Vale do Rio dos Sinos, Brasil

Alexandre Rocha da Silva, Universidade Federal do Rio Grande do Sul, Brasi Arthur Ituassu, Pontifícia Universidade Católica do Rio de Janeiro, Brasil Bruno Souza Leal, Universidade Federal de Minas Gerais, Brasil Elizabeth Bastos Duarte, Universidade Federal de Santa Maria, Brasil Francisco Paulo Jamil Marques, Universidade Federal do Ceará, Brasi Maurício Lissovsky, Universidade Federal do Rio de Janeiro, Brasil Suzana Kilpp, Universidade do Vale do Rio dos Sinos, Brasil Vander Casaqui, Escola Superior de Propaganda e Marketing, Brasil

EDIÇÃO DE TEXTO E RESUMOS I Susane Barros SECRETÁRIA EXECUTIVA I Helena Stigger EDITORAÇÃo ELETRÔNICA I Roka Estúdio
COMPÓS I www.compos.org.br

Associação Nacional dos Programas de Pós-Graduação em Comunicação

Presidente

Eduardo Morettin

Universidade de São Paulo, Brasil

eduardomorettin@usp.br

Vice-presidente

Inês Vitorino

Universidade Federal do Ceará, Brasil

ines@ufc.br

Secretária-Geral

Gislene da Silva

Universidade Federal de Santa Catarina, Brasil

gislenedasilva@gmail.com 